\title{
Anabases
}

ANABASES Traditions et réceptions de l'Antiquité

$9 \mid 2009$

Varia

\section{Études sur l'œuvre et la correspondance de Joseph Déchelette}

Introduction

Sandra Péré-Noguès

\section{(2) OpenEdition}

Journals

Édition électronique

URL : http://journals.openedition.org/anabases/438

DOI : 10.4000/anabases.438

ISSN : 2256-9421

Éditeur

E.R.A.S.M.E.

Édition imprimée

Date de publication : 1 mars 2009

Pagination : 201-203

ISSN : 1774-4296

\section{Référence électronique}

Sandra Péré-Noguès, "Études sur l'œuvre et la correspondance de Joseph Déchelette », Anabases [En ligne], 9 | 2009, mis en ligne le 01 mars 2012, consulté le 21 octobre 2019. URL : http:// journals.openedition.org/anabases/438; DOI : 10.4000/anabases.438

(c) Anabases 


\section{Études sur l'œuvre et la correspondance de Joseph Déchelette. Introduction}

Sandra Péré-Noguès

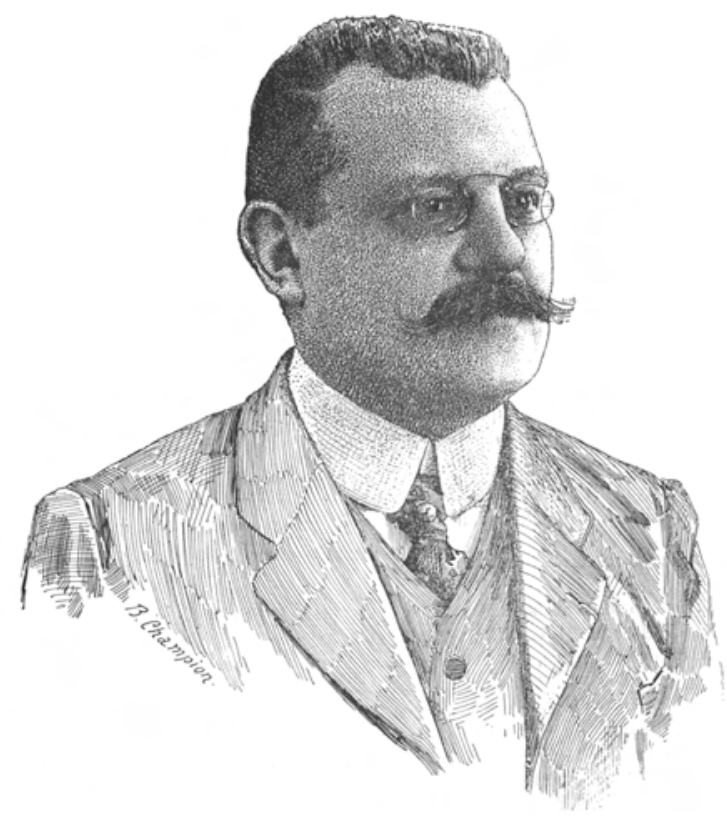

La journée d'ÉTUdes ORganisée le 29 avril 2008 à Toulouse par l’axe « Protohistoire et Mondes anciens » du laboratoire TRACES est à l'origine de ce dossier, constitué de quelques-unes des communications qui y ont été présentées ${ }^{1}$. Fondée sur un projet engagé

Nous tenons à remercier les autres orateurs (Corinne Bonnet, Véronica Ciccolani, Philippe Boissinot et Lionel Izac-Imbert) qui ont tous contribué à la réussite de cette journée, ainsi que Micheline Petiot, Marie-Agnès Gaidon-Bunuel, Vincent Guichard, Pierre-Yves Milcent, François Bon, Sébastien Dubois et Michel Vaginay pour leur participation active. 
par le laboratoire TRACES, la bibliothèque de Roanne et le Centre Européen d'archéologie de Bibracte, qui s'inscrit dans le renouveau des études historiographiques consacrées à la Préhistoire et à la Protohistoire, cette journée a été l'occasion de redécouvrir non seulement l'œuvre de Joseph Déchelette et son inscription dans le paysage de l'archéologie française et européenne d'avant 1914, mais aussi la personnalité d'un archéologue dont le parcours intellectuel et scientifique resta en marge du milieu universitaire ${ }^{2}$. La contribution de Serge Lewuillon essaie ainsi d'interpréter les cheminements de son travail scientifique tant sur le plan de la méthode qu'il mit en œuvre que sur celui de la pratique archéologique acquise lors des fouilles du Mont-Beuvray. L'auteur donne ici un point de vue original en insistant sur une démarche qui a cherché à concilier archéologie et érudition sans oublier l'approche historique, aspect souvent négligé de l'œuvre d'un des pionniers de la Protohistoire.

C'est dans une perspective historiographique plus générale que John Collis examine l'œuvre du conservateur de Roanne: si Joseph Déchelette n'innove pas dans le champ disciplinaire de l'archéologie, il a réussi à exploiter le meilleur de ce que donnaient les avancées de son temps et à l'utiliser dans son étude sur les Celtes, plus particulièrement sur l'origine de leur art.

Ce dossier permet aussi de rendre compte des premiers résultats d'une enquête menée sur la correspondance passive de Joseph Déchelette, correspondance qui est aujourd'hui conservée à la bibliothèque du musée de Roanne. Soigneusement reliée et classée dans des volumes in quarto juste après la disparition de Joseph Déchelette, cette correspondance ${ }^{3}$ fait l'objet depuis quelques mois d'une exploration des différents réseaux européens dans lesquels fut intégré Joseph Déchelette. Notre contribution vise à fournir quelques repères, une analyse plus exhaustive de l'ensemble des correspondants étant en cours d'élaboration.

Parmi les nombreuses relations épistolaires que Joseph Déchelette avait nouées, la correspondance avec Émile Espérandieu ${ }^{4}$ a pu être reconstituée dans sa presque totalité

2 Né le 8 janvier 1862 à Roanne, il était issu d'une famille d'industriels du textile. Alors qu'il était promis à une carrière toute tracée dans l'entreprise familiale, sa passion pour l'archéologie et son attachement à la région forézienne l'amenèrent à réaliser très tôt plusieurs recherches sur l'histoire et l'art dans sa région. Devenu par décision municipale conservateur adjoint pour l'archéologie du musée de Roanne en 1892, il en réorganisa et développa les collections durant vingt-deux années. Sur la vie de Joseph Déchelette, voir Marie-Suzanne BinéTruy, De l'art roman à la Préhistoire. Des sociétés savantes à l'Institut, itinéraires de Joseph Déchelette, Lyon, 1994.

3 Elle compterait plus de 3000 lettres, mais il s'agit d'un chiffre approximatif.

4 La correspondance d'Émile Espérandieu est conservée au palais du Roure à Avignon et offre par le nombre des lettres et des correspondants un fonds tout aussi exceptionnel que celui de Roanne. 
et offre un exemple instructif des liens de sociabilité savante qui pouvaient se tisser, comme le montre l'étude proposée par Marianne Altit-Morvillez.

Cette correspondance passive, à laquelle il faut ajouter d'autres courriers épars et des lettres de Joseph Déchelette lui-même, appartient à un fonds d'archives plus important qui réunit d'autres témoignages des activités scientifiques et des multiples voyages de l'archéologue (photographies, carnets...). L'ensemble n'est aujourd'hui pas complètement inventorié, mais il s'agit d'une des priorités du programme collectif de recherche dans lequel nos trois équipes (TRACES, Bibracte et bibliothèque de Roanne) sont impliquées.

La bibliothèque conserve aussi l'ensemble du fonds documentaire que Joseph Déchelette avait patiemment développé, et qui continue à être enrichi grâce à Micheline Petiot, l'actuelle bibliothécaire. Véritable lieu de mémoire, cette bibliothèque donne à voir ce qu'était l'atelier d'un " archéologue de province ", dont la renommée dépassa rapidement le cadre régional et suscita d'innombrables relations épistolaires à travers toute la France et l'Europe.

Les contributions rassemblées dans ce dossier sont pour l'essentiel des recherches inédites sur l'œuvre et la personnalité de Joseph Déchelette, qui souhaitent à la fois privilégier des approches historiographiques originales et valoriser un lieu d'études, la bibliothèque du musée de Roanne, ainsi que son fonds documentaire et ses archives, l'ensemble restant à bien des égards exceptionnel sur le plan national.

Que l'équipe éditoriale de la revue Anabases soit remerciée d'avoir accepté d'être associée à ce projet et d'avoir accordé une place dans ses pages à un honnête homme et à un savant inclassable, Joseph Déchelette.

Sandra Péré-Noguès

Maison de la Recherche

Laboratoire TRACES (UMR 5608)

5 allées Antonio Machado

F-31058 Toulouse

perenog@univ-tlse2.fr 